\title{
Respiratory System Findings Method
}

National Cancer Institute

\section{Source}

National Cancer Institute. Respiratory System Findings Method. NCI Thesaurus. Code C123980.

The technique used to administer the respiratory system assessment. 